\title{
Season of birth and handedness in Serbian high school students Sanja Milenković* ${ }^{*}$, Daniel Rock ${ }^{\dagger 2,3}$, Milan Dragović ${ }^{\dagger 2,3}$ and Aleksandar Janca ${ }^{\dagger 2}$
}

Address: ${ }^{1}$ Institute for Hygiene and Medical Ecology, School of Medicine, University of Belgrade, Serbia, ${ }^{2}$ School of Psychiatry and Clinical Neurosciences, University of Western Australia, Australia and ${ }^{3}$ Centre for Clinical Research in Neuropsychiatry, Graylands Hospital, Western Australia, Australia

Email: Sanja Milenković* - sanjavecko@yahoo.com; Daniel Rock - daniel.rock@uwa.edu.au; Milan Dragović - milan.dragovic@uwa.edu.au; Aleksandar Janca - jancaa@meddent.uwa.edu.au

* Corresponding author †Equal contributors

Published: 30 january 2008

Annals of General Psychiatry 2008, 7:2 doi:10.1186/1744-859X-7-2

This article is available from: http://www.annals-general-psychiatry.com/content/7/I/2

(C) 2008 Milenković et al; licensee BioMed Central Ltd.

This is an Open Access article distributed under the terms of the Creative Commons Attribution License (http://creativecommons.org/licenses/by/2.0), which permits unrestricted use, distribution, and reproduction in any medium, provided the original work is properly cited.
Received: 13 November 2007

Accepted: 30 january 2008

\begin{abstract}
Background: Although behavioural dominance of the right hand in humans is likely to be under genetic control, departures from this population norm, i.e. left- or non-right-handedness, are believed to be influenced by environmental factors. Among many such environmental factors including, for example, low birth weight, testosterone level, and maternal age at birth, season of birth has occasionally been investigated. The overall empirical evidence for the season of birth effect is mixed.
\end{abstract}

Methods: We have investigated the effect of season of birth in an epidemiologically robust sample of randomly selected young people $(n=977)$, all born in the same year. A Kolmogorov-Smirnov type statistical test was used to determine season of birth.

Results: Neither the right-handed nor the non-right-handed groups demonstrated birth asymmetry relative to the normal population birth distribution. There was no between-group difference in the seasonal distribution of birth when comparing the right-handed to the non-righthanded groups.

Conclusion: The present study failed to provide support for a season of birth effect on atypical lateralisation of handedness in humans.

\section{Background}

Functional dominance of the right hand is the norm across different populations, various geographical regions, and diverse cultures, with approximately $90 \%$ of humans exhibiting clear dominance of the right side of the body. This behavioural characteristic is considered as uniquely human, as there is no other species that displays such a large behavioural asymmetry at the population level. It is also widely accepted that this behavioural feature emerged at some point during the hominid evolu- tion, and that this feature preceded the evolution of another uniquely human feature - language, and in particular, speech as its central component [1].

The transmission of handedness over many generations of humans is widely believed to be under genetic control [2$4]$, rather than resulting from learning. Converging lines of evidence provide support for the genetic hypothesis, including imaging studies on twins [5], meta-analysis of handedness in twins [6], and molecular genetic studies 
$[7,8]$. To date, however, no gene for handedness has been identified. Genetic models of handedness [2,3] argue that the functional advantage of the right hand originates from a purely genetic effect, while left-handedness is a consequence of a random shift in hand dominance. Theory suggests that in individuals without the genetic disposition, both cerebral and hand dominance are randomly assigned. An implication of these models is that left-sided behavioural dominance is a benign genetic consequence, but not a pathology acquired during early brain development. Moreover, these models also argue that left-handedness may be beneficial. For example, there is empirical support for the notion that left-handers are somewhat better in visuospatial and visuomotor abilities than righthanders This may explain why left-handers are overrepresented in some groups with high demand on spatial skills such as architects [9], tennis players and cricketers [10], and musicians [11]. In contrast to purely genetic models, the shift away from the "default" right-handedness has occasionally been labelled as "anomalous" (e.g. [12]), "alinormal" (e.g. [13]), or "atypical" (e.g. [14]). The increased prevalence of left-handedness in populations with some medical conditions (e.g. Rett syndrome, schizophrenia, autism) is believed to originate from pathological processes that either overpower or disrupt the genetics of hand dominance.

The environmental factors believed to provide structural brain substrate for left-handedness include birth difficulties [15], prenatal ultrasound [16], maternal smoking during pregnancy [17], low birth weight [18,19], diffuse brain damage [20], and testosterone level during early development [12]. Another factor that has occasionally been considered as "trigger" for atypical lateralisation of hand preferences is season of birth. That season of birth can be a serious risk factor has already been established for various conditions, including brain tumours [21], proneness to road accidents [22], and schizophrenia [23]. How season of birth may exert an influence on cerebral lateralisation is less clear. Season of birth may be conceptualised as a portmanteau term covering various environmental variables such as prenatal exposure to various hormones (e.g. testosterone), incidence of diseases, nutrition, and reproductive activity in humans. For obvious reasons, direct investigations between these factors and behavioural lateralisation are not always feasible. It has therefore been hypothesised that variation in the incidence of viral infections $[24,25]$ and prenatal exposure to testosterone [12] may be responsible for sinistral developmental trajectory. Similar to all other environmental factors responsible for left-handedness, the empirical evidence for the season of birth effect is indirect, speculative and, at best, mixed. In this paper we describe the effect of season of birth on atypical lateralisation of hand preferences in a large sample of students all born in the same year.

\section{Methods \\ Aim of the study}

The aim of this study is to examine season of birth as a risk factor for hand preference. We used a population-representative random sample of high school students, grouped according to hand preference. We compared their birth distribution with the corresponding age-matched birth distribution in the general population.

\section{Participants}

A total of 1224 high school students participated in this study. The sample comprised all year 9 students (mean age $=15.0$ years, $\mathrm{SD}=0.4$ ) from six randomly selected high schools in Belgrade, Serbia. Students born in 1989 and 1991 and those with a missing date of birth were excluded from analysis, leaving thus 977 students born in a single year (1990). The reduced sample comprised 457 males (9.4\% left-hand writers) and 520 females (5.4\% left-hand writers). Whole population birth data were provided by the Statistical Office of the Republic of Serbia.

\section{Assessment}

Handedness was assessed by the Edinburgh Handedness Inventory [26]. This inventory comprises 10 items for hand preference and two additional laterality preferences (eye and foot) that were excluded from analysis. On each item participants indicated their hand preference in the following range: strong $(++)$, less strong $(+)$, to indifferent $(+/+)$. Laterality quotients ranging from -100 (left-handedness) to +100 (right-handedness) were computed for each subject in the study, using the standard expression $\mathrm{LQ}=(\mathrm{R}-\mathrm{L}) /(\mathrm{R}+\mathrm{L}) * 100$. Subjects $(\mathrm{n}=247)$ with laterality quotients in the range -100 to +50 were considered as clearly not right-hand dominant, while the remaining subjects (from +51 to +100 ) were classified as consistent right-handers $(\mathrm{n}=730)$. This classification of subjects is based on neurological and neurobehavioural research $[5,9,12]$ that supports the notion of a taxonic structure of hand preferences, i.e. strong right and non-right. To separate strong right-handers from non-right-handers, a conservative threshold for determination of non-righthandedness was selected [27]. The small number of exclusive left-handers in the sample precluded the analysis of these as a separate birth group.

\section{Determination of season of birth}

Date of birth was collapsed into a single 12-month frequency series. Season of birth was determined using a Kolmogorov-Smirnov type statistical test [28]. This test has been proposed as a more specific test of the curvilinear variation that is characteristic of birth series and has been used in other seasonality studies (e.g. [29-31]). Since this method compares the cumulative proportional difference curves between two contemporaneous time series, it can accommodate the variable population of risk approach. 
Variable population of risk adjustment was achieved by comparing the birth distribution of "handedness" groups with whole population data, again collapsed into a single 12-month frequency series. All of the "handedness" group are a single birth cohort, born in the same year. National population live birth data for the same birth year was used as the index, or expected birth distribution. Using this approach, we can determine whether there is a significant difference in the frequency distribution of birth months between the handedness sub-groups and the general population variation of births by month. Data were adjusted to a standard 31-day month to eliminate the "calendar effect" [32].

\section{Results}

Neither the right-handed nor the non-right-handed groups showed a birth asymmetry relative to the normal population birth distribution. Furthermore, there was no between-groups difference in the seasonal distribution of birth comparing the right-handed to the non-righthanded groups. Figure $1 \mathrm{a}-\mathrm{c}$ shows the cumulative proportional difference in the two sub-samples compared with the general population $(\mathrm{a}, \mathrm{b})$ and with each other $(\mathrm{c})$.

\section{Discussion}

The results of the present study do not support an association between the distribution of handedness and season of birth in young people.

It is worth noting that all of our analyses are based on a sample of subjects who were all born in a single year and compared with whole of population birth distribution for the same year. As far as we are aware, this is the first study to use this procedure within a variable population at risk model. Most season of birth studies create a composite reference population, summing the different normal population yearly birth distributions for the age range of the dependent group [33]. In such a situation it can be difficult to definitively conclude that any seasonal difference between two composite birth distributions is related to the dependent sample, and is not merely an artefact associated with the "constructed" reference population. Furthermore, the sample comprised a randomly selected subset of all school-age children from Belgrade. Again, this approach has not been used previously to study season of birth effects in handedness. Others, for well-understood reasons, tend to use convenience samples. The effect such methodological differences may have has not been systematically studied in the seasonality literature, however, the advantages of random sampling, per se, have been well described (e.g. [34]).

Although there is some evidence for a season of birth effect on human handedness, the empirical data are inconclusive as there are studies showing contradictory
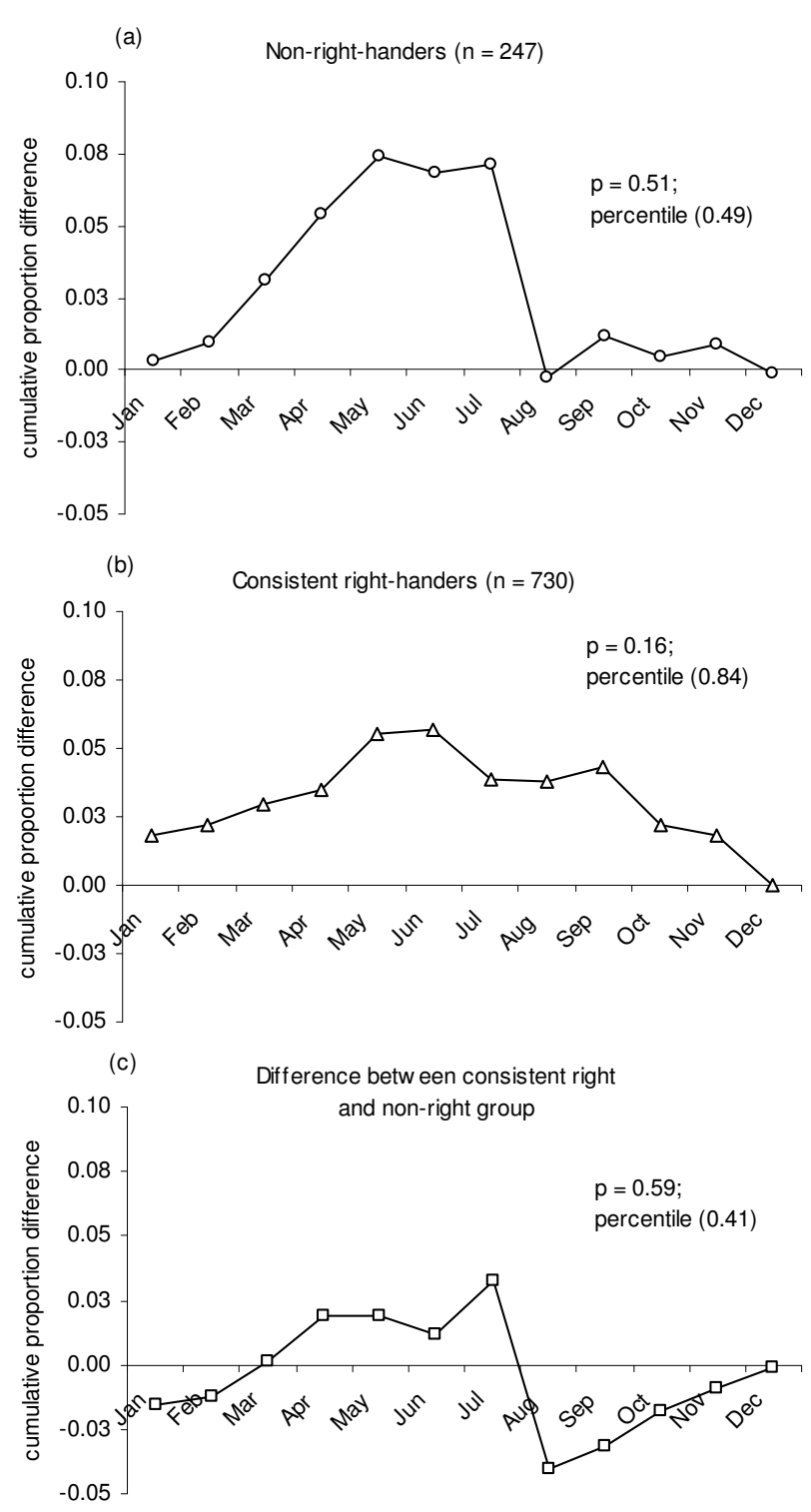

Figure I

Cumulative proportional differences. Cumulative proportional difference between the birth distribution for the dependent samples, (a) non-right-handed and (b) righthanded, and the normal whole population distribution of births for the same birth year (1990) are shown. (c) Cumulative proportional difference between the two dependent birth distributions.

results. For example, several published studies $[24,25,35,36]$ have suggested that distribution of birth is different in left-handers than in right-handers, whereas some studies reported a gender specific association (e.g. [25,37]). By contrast, quite a few studies [38-40], including some that have re-examined previously published results (e.g. [41]), failed to confirm the pathogenic effect of season of birth on atypical hand dominance. The lack 
of empirical consistency of findings makes this factor, which potentially may explain a certain proportion of variation in human handedness, remain obscure.

In conclusion, we found no evidence that season of birth possess an aetiological relevance for developing atypical lateralisation of hand preferences.

\section{Competing interests}

The author(s) declare that they have no competing interests.

\section{Authors' contributions}

The authors all contributed equally to the manuscript, were all involved in the drafting of the manuscript and gave final approval on the manuscript.

\section{References}

I. Corballis MC: From mouth to hand: gesture, speech, and the evolution of right-handedness. Behav Brain Sci 2003, 26: 199-208.

2. Annett M: Left, Right, Hand and Brain: The Right Shift Theory Hillsdale, New Jersey: Lawrence Erlbaum Associates Ltd; 1985.

3. McManus IC: Handedness, language dominance and aphasia: a genetic model. Psychol Med 1985

4. Corballis MC: The genetics end evolution of handedness. Psychol Rev 1997, 104:7|4-727.

5. Geschwind HD, Miller LB, DeCarli C, Carmelli D: Heritability of lobar brain volumes in twins supports genetic model of cerebral laterality and handedness. Proc Natl Acad Sci USA 2002, 99:3176-3181.

6. Sicotte NL, Woods RP, Mazziotta JC: Handedness in twins: a meta-analysis. Laterality 1999, 4:265-286.

7. Francks C, Fisher SE, MacPhie L, Richardson AJ, Marlow AJ, Stein JF, Monaco AP: A genomewide linkage screen for relative hand skill in siblings pairs. Am J Hum Genet 2002, 70:800-805.

8. Francks C, DeLisi LE, Fisher SE, Laval SH, Rue JE, Stein JF, Monaco AP. Confirmatory evidence for linkage of relative hand skill to 2p I 2-q I I. Am J Hum Genet 2003, 72:499-502.

9. Schachter SC, Ransil BJ: Handedness distributions in nine professional groups. Percept Mot Skills 1996, 82:5I-63.

10. Wood C], Aggleton JP: Handedness in 'fast ball' sports: do left handers have an innate advantage? Br J Psychology 1989, 80:227-240.

II. Aggleton JP, Kentrige RW, Good JMM: Handedness and musical ability: a study of professional orchestral players, composers and choir members. Psychol Music 1994, 22:148-156.

12. Geschwind N, Galaburda MA: Cerebral lateralisation: biological mechanisms, associations, and pathology: I. A hypothesis and a program for research. Arch Neurol 1985, 42:428-459.

13. Coren S: The Left-Hander Syndrome: The Causes And Consequences Of Left-Handedness New York: The Free Press; 1992.

14. Satz P, Green MF: Atypical handedness in schizophrenia: some methodological and theoretical issues. Schizophr Bull 1999, 25:63-78.

15. Bakan P: Are left-handers brain damaged? New Sci 1975, 67:200-202.

16. Kieler H, Cnattingius S, Haglund B, Palmgren J, Axelsson O: Sinistrality - a side-effect of prenatal sonography: a comparative study of young men. Epidemiology 2001, I 2:618-623.

17. Bakan P: Handedness and maternal smoking during pregnancy. Int J Neurosci I99I, 56:I6I-I68.

18. O'Callaghan MJ, Burn YR, Mohay HA, Rogers Y, Tudehope DI: Handedness in extremely low birth weight infants: aetiology and relationship to intellectual abilities, motor performance and behaviour at four and six years. Cortex 1993, 29:629-637.

19. Powls A, Botting N, Cooke RW, Marlow N: Handedness in verylow-birthweight (VLBW) children at 12 years of age: relation to perinatal and outcome variables. Dev Med Child Neurol 1996 , 38:594-602.
20. Satz P, Orsini DL, Saslow E, Henry R: The pathological left-handedness syndrome. Brain Cogn 1985, 4:27-46.

21. Koch HJ, Klinkhammer_Schalke M, Hofstadter F, Bogdhan U, Hau P: Seasonal patterns of birth in patients with glioblastoma. Chronobiol Int 2006, 23:1047-1052.

22. Radun I, Radun JE: Seasonal variation of falling asleep while driving: an examination of fatal road accidents. Chronobiol Int 2006, 23:1053-1064.

23. Davies G, Welham J, Chant D, Torrey EF, McGrath J: A systematic review and meta-analysis of Northern Hemisphere season of birth studies in schizophrenia. Schizophr Bull 2003, 29:587-593.

24. Leviton A, Kilty T: Seasonal variation in the birth of left-handed schoolgirls. Arch Neurol 1979, 36: I I5-I I6.

25. Badian NA: Birth order, maternal age, season of birth, and handedness. Cortex 1983, 19:451-463.

26. Oldfield RC: The assessment and analysis of handedness: The Edinburgh Inventory. Neuropsychologia 1971, 9:97- I I3.

27. Dragovic $M$ : Categorisation and validation of handedness using latent class analysis. Acta Neuropsychiatr 2004, I 6:2 I 2-2 I 8.

28. Freedman LD: The use of a Kolmogorov-Smirnov type statistic in testing hypotheses about seasonal variation. I Epidemiol Community Health 1979, 33:223-228.

29. Verdoux H, Takei N, Cassou de Saint-Mathurin R, Murray RM, Bourgeois ML: Seasonality of birth in schizophrenia: the effect of regional population density. Schizophr Res 1997, 23: I75-I80.

30. Daniels BA, Kirkby KC, Mitchell P, Hay D, Mowry B: Seasonal variation in hospital admission for bipolar disorder, depression and schizophrenia in Tasmania. Acta Psychiatr Scand 2000, 1 02:38-43.

31. Rock D, Greenberg D, Hallmayer J: Season of birth and the seasonality of suicidal behaviour in Western Australia. Eur Arch Psychiatry Clin Neurosci 2006, 256:98-105.

32. Cleveland WS, Devlin S: Calendar effects in monthly time series: detection by spectrum analysis and graphical methods. J Am Stat Assoc 1980, 75:487-495.

33. Torrey EF, Miller J, Rawlings R, Yolken RH: Seasonality of births in schizophrenia and bipolar disorder: a review of the literature. Schizophr Res 1997, 28:1-38.

34. Moser CA, Kalton G: Survey methods in social investigation Aldershot, UK: Gower; 1985.

35. Nicholls MER: Seasonal trends in the birth of sinistrals. Laterality I998, 3:24I-253.

36. Martin M, Jones GV: Handedness and season of birth: a genderinvariant relation. Cortex 1999, 35:123-128.

37. Rogerson PA: On the relationship between handedness and season of birth for men. Percept Mot Skills 1994, 79:499-506.

38. Dellatolas G, Curt F, Lellouch J: Birth order and month of birth are not related with handedness in a sample of 9370 young men. Cortex 1991, 27:139.

39. Cosenza RM, Mingoti SA: Season of birth and handedness revisited. Percept Mot Skills 1995, 8 I:475-480.

40. Abel EL, Kruger ML: Relation of handedness with season of birth of professional baseball players revisited. Percept Mot Skills 2004, 98:44-46.

4I. Hicks RA, Dusek C, Larsen F, Pellegrini RJ: Reliability of seasonal variation in births of left-handed women. Percept Mot Skills 1980, 50:81-82.

Publish with Bio Med Central and every scientist can read your work free of charge

"BioMed Central will be the most significant development for disseminating the results of biomedical research in our lifetime. "

Sir Paul Nurse, Cancer Research UK

Your research papers will be:

- available free of charge to the entire biomedical community

- peer reviewed and published immediately upon acceptance

- cited in PubMed and archived on PubMed Central

- yours - you keep the copyright 